\title{
ARTICLE
}

\section{Measurement of Neutron Cross Sections for Yttrium and Terbium at $287 \mathrm{MeV}$}

\author{
Shun SEKIMOTO ${ }^{*}$, Takashi UTSUNOMIYA ${ }^{1}$, Hiroshi YASHIMA ${ }^{1}$, Kazuhiko Ninomiya ${ }^{2}$, Takashi OMOTO ${ }^{3}$, \\ Reiko NAKAGAKI ${ }^{3}$, Tatsushi SHIMA ${ }^{4}$, Naruto TAKAHASHI ${ }^{3}$, Atsushi SHINOHARA ${ }^{3}$, Norikazu KINOSHITA ${ }^{5}$, \\ Hiroshi MATSUMURA ${ }^{5}$, Daiki Satoh ${ }^{2}$, Yosuke Iwamoto ${ }^{2}$, Masayuki HAGIWARA ${ }^{5}$, Kunihiko NISHIIZUMI ${ }^{6}$, and \\ Seiichi SHIBATA ${ }^{1}$,

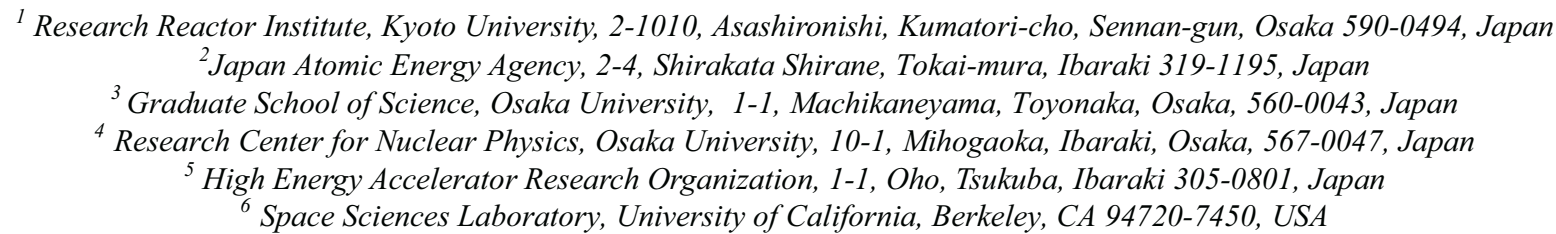

Reaction cross sections for $\mathrm{Y}$ and $\mathrm{Tb}$ induced by neutrons at $287 \mathrm{MeV}$ were measured by using ${ }^{7} \mathrm{Li}(\mathrm{p}, \mathrm{n})$ reaction at N0 beam line in the Research Center for Nuclear Physics (RCNP), Osaka University. To estimate quasi-monoenergetic neutron-induced cross sections, these samples were irradiated on the two angles of 0 degree and 30 degrees for the axis of the primary proton beam. Proton-induced reaction cross sections for these elements at $300 \mathrm{MeV}$ were also measured. The measured cross section data in the ${ }^{89} \mathrm{Y}(\mathrm{p}, \mathrm{x})$ and ${ }^{89} \mathrm{Y}(\mathrm{n}, \mathrm{x})$ reactions are evaluated by the reference values. Those in the ${ }^{159} \mathrm{~Tb}(\mathrm{n}, \mathrm{x})$ reaction are compared with those in the ${ }^{159} \mathrm{~Tb}(\mathrm{p}, \mathrm{x})$ reaction.

\section{KEYWORDS: neutron-induced reaction cross section, proton-induced reaction cross section, $287 \mathrm{MeV}$ quasi-monoenergetic neutron}

\section{Introduction}

Neutron-induced reaction cross sections are important as basic nuclear data for the estimation of residual radioactivities in the accelerator facility ${ }^{1)}$. Those data are also essential in the field of cosmochemistry for deciphering of the cosmic-ray irradiation history by evaluating the amounts of cosmogenic nuclides stored in extraterrestrial matters $^{2)}$. However, neutron cross sections in the energy range above $100 \mathrm{MeV}$ have scarcely been measured experimentally except for those from $\mathrm{C}, \mathrm{Cu}, \mathrm{Pb}$ and $\mathrm{Bi}$ targets $^{3,4)}$. Therefore, those obtained from calculation codes are utilized and proton cross section data are also utilized on the basis of the assumption that neutron cross sections in higher energies than $100 \mathrm{MeV}$ approximately equal to proton ones in the same energy range.

In this work, we measured reaction cross sections for $\mathrm{Y}$ and $\mathrm{Tb}$ induced by neutrons at $287 \mathrm{MeV}$, which have never been reported. Furthermore, proton-induced cross sections for these elements at $E_{p}=300 \mathrm{MeV}$ were also measured to compare their values with the neutron ones.

\section{Experiment}

\section{Neutron irradiation}

The irradiation experiments were carried out using neutrons produced through ${ }^{7} \mathrm{Li}(\mathrm{p}, \mathrm{n})$ reaction at N0 beam line in the Research Center for Nuclear Physics (RCNP), Osaka University. To estimate quasi-monoenergetic neutron induced cross sections, the sample stacks of $\mathrm{Y}$ and $\mathrm{Tb}$ were

*Corresponding Author, E-mail:sekimoto@rri.kyoto-u.ac.jp

(C) Atomic Energy Society of Japan irradiated on the two angles of 0 degree and 30 degrees for the axis of the primary proton beam ${ }^{5}$. The schematic view of these irradiation configurations described above is shown in Fig. 1.

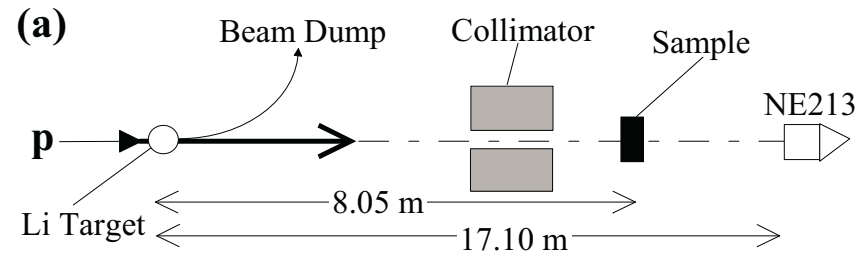

(b)

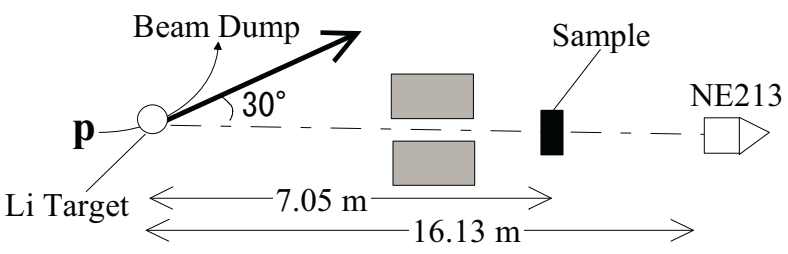

Fig. 1 Schematic view of irradiation configurations; (a) 0-deg. and (b) 30-degs.

This irradiation method referred to the method by Sisterson et al. ${ }^{6}$. Since peak energy neutrons produced by ${ }^{7} \mathrm{Li}(\mathrm{p}, \mathrm{n})$ reaction are tend to be emitted forward and low energy neutron isotropically, the irradiation on the angle of 0 degree were performed by peak and low energy neutrons, whereas the irradiation on 30 low energy ones only. Therefore, neutron cross sections were able to be estimated by subtracting the activities produced in the samples placed on 30 degrees from those of 0 degree to correct the contribution 
of the low energy tail in the neutron spectrum.

The neutron energy spectra were measured by the time-of-flight method using a NE213 liquid scintillation detector placed at 17.10 or $16.13 \mathrm{~m}$ from the Li-target in the forward direction at 0 degree or 30 for the axis of the primary proton beam (shown in Fig. 1). The neutron spectra obtained in the irradiation on the angle of 0 degree and 30 are shown in Fig. 2(a). The quasi-monoenergetic neutron spectrum obtained by subtracting the spectrum in 30 degrees from the one in 0 is shown in Fig. 2(b).
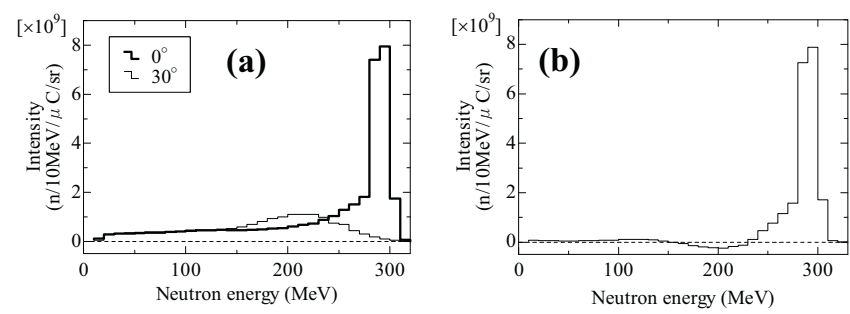

Fig. 2 (a) Neutron spectra of the $0^{\circ}$ and $30^{\circ}$ irradiation measured with the TOF method (b) Quasi -monoenergetic neutron spectrum obtained from the spectra of the $0^{\circ}$ and $30^{\circ}$ irradiation

The samples were placed at 8.05 or $7.05 \mathrm{~m}$ from the Li-target in the forward direction at 0 degree or 30 for the axis of the primary proton beam (shown in Fig. 1). Those samples were irradiated for 26 hours on the angle of 0 degree or for 18 hours on 30 .

\section{Proton irradiation}

The samples were mounted in the holder where the Li-target was mounted in the neutron irradiation and irradiated for 90 seconds. In the proton irradiation, both on-beam samples and off-beam ones were prepared. Proton-induced reaction cross sections were estimated by subtracting the activities produced in off-beam ones from those in on-beam.

During the neutron and proton irradiation the proton beam current at the beam dump was recorded by the digital current integrator, connected to a multi-channel scaler (MCS) with the dwelling time of 30 seconds, to monitor the fluctuations of proton beam currents.

3. $\gamma$-ray spectrometry

After the irradiation, $\gamma$ rays emitted from the irradiated samples were measured with a high-purity germanium (HPGe) detector. The neutron-irradiated samples were counted for 1000-230000 seconds more than ten times, and the proton-irradiated ones for 7000-17000 seconds several times. The measured nuclides in the neutron- and protonirradiated samples are listed in Table 1 with their physical properties.

\section{Data analysis}

\section{Reaction rate in neutron-irradiated samples}

Activation reaction rates were estimated by considering the peak counts of gamma-ray spectra measured with the HPGe detector, the peak efficiency of the HPGe detector
Table 1 Physical properties of measured nuclides

\begin{tabular}{cccccc}
\hline $\begin{array}{c}\text { Target } \\
\text { nuclides }\end{array}$ & Reaction & $\begin{array}{c}\text { Measured } \\
\text { nuclides }\end{array}$ & Half-Life & $\begin{array}{c}\text { Gamma-ray } \\
\text { energy[keV] }\end{array}$ & $\begin{array}{c}\text { Branching } \\
\text { ratio[\%] }\end{array}$ \\
\hline${ }^{89} \mathrm{Y}$ & $(\mathrm{p}, \mathrm{x})$ & ${ }^{88} \mathrm{Y}$ & 106.6 day & 1836 & 99 \\
${ }^{89} \mathrm{Y}$ & $(\mathrm{p}, \mathrm{x})$ & ${ }^{83} \mathrm{Rb}$ & 86.2 day & 520 & 45 \\
${ }^{89} \mathrm{Y}$ & $(\mathrm{p}, \mathrm{x})$ & ${ }^{75} \mathrm{Se}$ & 119.6 day & 265 & 59 \\
${ }^{89} \mathrm{Y}$ & $(\mathrm{p}, \mathrm{x})$ & ${ }^{74} \mathrm{As}$ & 17.8 day & 596 & 59 \\
${ }^{89} \mathrm{Y}$ & $(\mathrm{p}, \mathrm{x})$ & ${ }^{65} \mathrm{Zn}$ & 244.3 day & 1115 & 51 \\
${ }^{89} \mathrm{Y}$ & $(\mathrm{n}, \mathrm{x})$ & ${ }^{77} \mathrm{Br}$ & 57.0 hour & 239 & 23 \\
${ }^{89} \mathrm{Y}$ & $(\mathrm{n}, \mathrm{x})$ & ${ }^{75} \mathrm{Br}$ & 1.6 hour & 287 & 88 \\
${ }^{89} \mathrm{Y}$ & $(\mathrm{n}, \mathrm{x})$ & ${ }^{72} \mathrm{As}$ & 26.0 hour & 834 & 80 \\
${ }^{159} \mathrm{~Tb}$ & $(\mathrm{p}, \mathrm{x}),(\mathrm{n}, \mathrm{x})$ & ${ }^{149} \mathrm{Gd}$ & 9.3 day & 150 & 48 \\
${ }^{159} \mathrm{~Tb}$ & $(\mathrm{p}, \mathrm{x}),(\mathrm{n}, \mathrm{x})$ & ${ }^{148} \mathrm{Eu}$ & 55.6 day & 550 & 99 \\
${ }^{159} \mathrm{~Tb}$ & $(\mathrm{p}, \mathrm{x}),(\mathrm{n}, \mathrm{x})$ & ${ }^{147} \mathrm{Eu}$ & 24.6 day & 197 & 27 \\
${ }^{159} \mathrm{~Tb}$ & $(\mathrm{p}, \mathrm{x}),(\mathrm{n}, \mathrm{x})$ & ${ }^{145} \mathrm{Eu}$ & 5.9 day & 894 & 66 \\
\hline
\end{tabular}

calculated by EGS4 $\operatorname{codes}^{7)}$, the self-absorption of gamma rays in the samples also corrected by EGS4 codes and the beam current fluctuation during the irradiation.

The reaction rates per beam current, corrected for the above-mentioned effects, are given as follows:

$$
R=\frac{\lambda C}{N \varepsilon \gamma e^{-\lambda t_{c}}\left(1-e^{-\lambda t_{m}}\right) \sum_{i=1}^{n}\left\{Q_{i}\left(1-e^{-\lambda i \Delta t}\right) e^{-\lambda(n-i) \Delta t}\right\}}
$$

where $\lambda$ is a decay constant $\left(\mathrm{s}^{-1}\right), C$ is a total counts of gamma-ray peak area, $\varepsilon$ is a peak efficiency, $N$ is a number of atoms in the target (atom), $t_{c}$ is a cooling time (s), $\gamma$ is a branching ratio of gamma rays, $t_{m}$ is a measurement time (s), and $Q_{i}$ is a beam current for irradiation time interval $\Delta \mathrm{t}$.

\section{Cross section estimation in neutron-irradiated samples}

The activation cross section $(\sigma)$ can be determined in principle as follows:

$$
\sigma=\frac{R}{\varphi}
$$

where $\varphi$ is a neutron fluence rate per beam current.

Since neutron cross sections were estimated by subtracting the reaction rate in the irradiation on the angle of 30-degs from that in 0 -deg. In this work, the cross sections were estimated as follows:

$$
\sigma=\frac{R_{0}-R_{30} \mathrm{f}}{\varphi}
$$

where $R_{0}$ and $R_{30}$ are the reaction rate in the irradiation on the angles of 0 -deg. and 30-degs., respectively and $\mathrm{f}$ is a correction factor which cover the correction in subtraction of neutron spectrum, the one due to the variation from 17.10 to $16.13 \mathrm{~m}$ in the distance between the Li-target and the NE213 in the irradiation on the angles of 30-degs. and the one due to the variation from 8.05 to $7.05 \mathrm{~m}$ in the distance between the Li-target and the samples. 


\section{Cross section estimation in proton-irradiated samples}

The proton induced reaction cross sections were able to be estimated as follows:

$$
\sigma=\frac{A_{o n}-A_{o f f}}{I N_{d} x\left(1-e^{-\lambda t_{i}}\right)}
$$

where $I$ is a mean beam intensity during the proton irradiation $\left(\mathrm{s}^{-1}\right), N_{d}$ is an atomic density in the irradiated samples (atom $\cdot \mathrm{cm}^{-3}$ ), $x$ is a thickness of the irradiated samples $(\mathrm{cm}), t_{i}$ is an irradiation time $(\mathrm{s}), \lambda$ is a decay constant $\left(\mathrm{s}^{-1}\right), A_{\text {on }}\left(A_{\text {off }}\right)$ is an activity produced in the on-beam (off-beam) sample $(\mathrm{Bq})$. Those activities were estimated as follows:

$$
A=\frac{\lambda C}{\varepsilon \gamma e^{-\lambda t_{c}}\left(1-e^{-\lambda t_{m}}\right)}
$$

where symbols used in the equation (5) express same physical quantities as those used in the equation (1).

\section{Results and discussion}

\section{Proton cross sections in Yttrium}

The cross sections obtained for ${ }^{89} Y(p, x){ }^{88} Y,{ }^{89} Y(p, x){ }^{83} R b$, ${ }^{89} \mathrm{Y}(\mathrm{p}, \mathrm{x}){ }^{75} \mathrm{Se},{ }^{89} \mathrm{Y}(\mathrm{p}, \mathrm{x}){ }^{74} \mathrm{As}$ and ${ }^{89} \mathrm{Y}(\mathrm{p}, \mathrm{x}){ }^{65} \mathrm{Zn}$ reactions are shown in Fig. 3 through Fig. 7. From the comparison of those cross section data with reference values ${ }^{8-10)}$, it is found that the experimental values of cross sections for the five reactions described above agree well with the reference values.

\section{Neutron cross sections in Yttrium}

The cross sections obtained for ${ }^{89} \mathrm{Y}(\mathrm{n}, \mathrm{x}){ }^{77} \mathrm{Br},{ }^{89} \mathrm{Y}(\mathrm{n}, \mathrm{x}){ }^{75} \mathrm{Br}$ and ${ }^{89} \mathrm{Y}(\mathrm{n}, \mathrm{x}){ }^{72}$ As reactions are shown in Fig. 8 through Fig.

10. Since those neutron cross section data in the similar energy range as used in this work have never been reported, the experimental values are compared with reference values in proton-induced reaction cross sections ${ }^{11-13)}$.

Although the reference values are insufficient, the experimental values of ${ }^{89} \mathrm{Y}(\mathrm{n}, \mathrm{x}){ }^{77} \mathrm{Br}$ and ${ }^{89} \mathrm{Y}(\mathrm{n}, \mathrm{x}){ }^{72} \mathrm{As}$ reaction cross sections approximately agree with the reference values in the proton cross sections. The

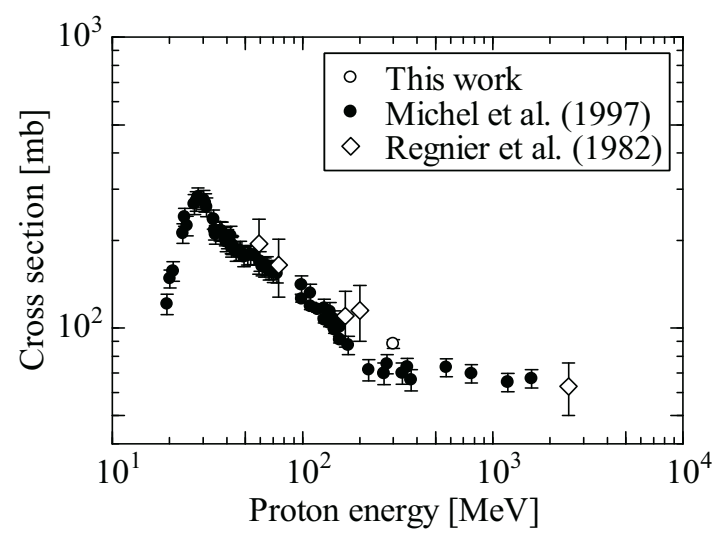

Fig. 3 Excitation function for ${ }^{89} \mathrm{Y}(\mathrm{p}, \mathrm{x})^{88} \mathrm{Y}$.

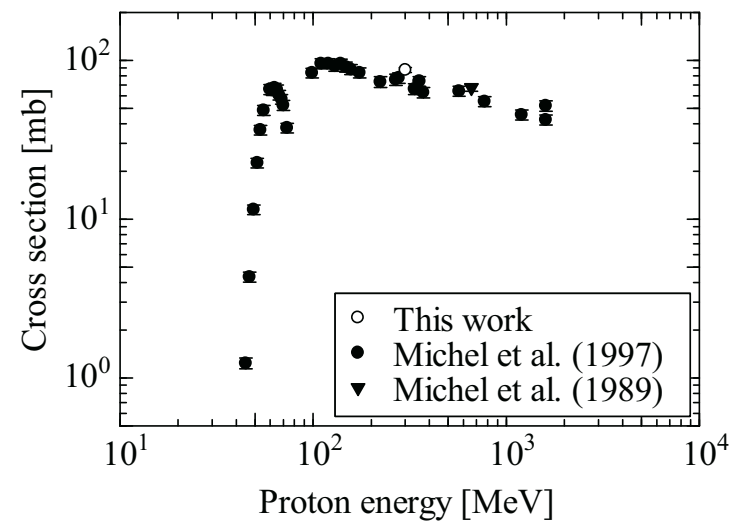

Fig. 4 Excitation function for ${ }^{89} \mathrm{Y}(\mathrm{p}, \mathrm{x})^{83} \mathrm{Rb}$.

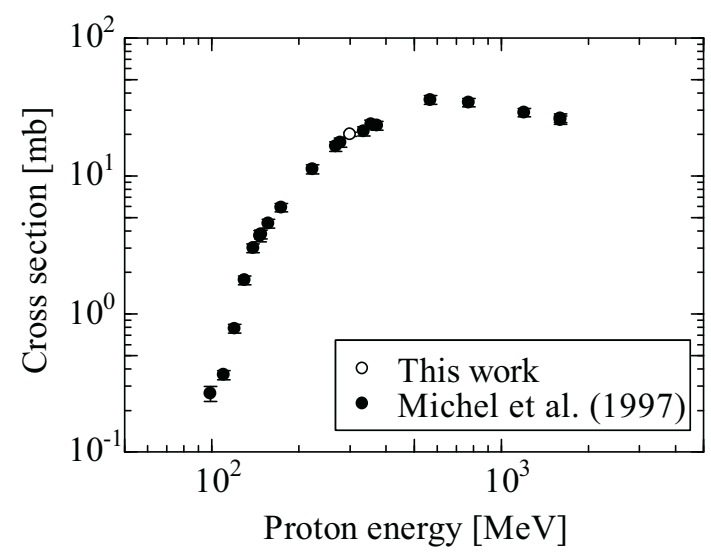

Fig. 5 Excitation function for ${ }^{89} \mathrm{Y}(\mathrm{p}, \mathrm{x})^{75} \mathrm{Se}$.

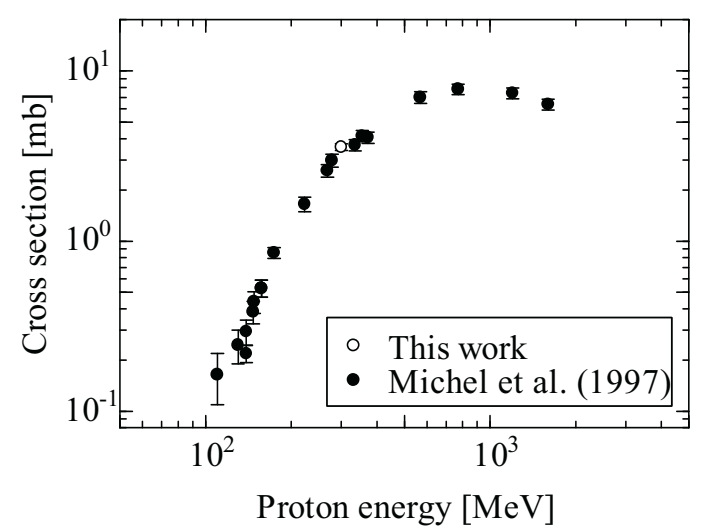

Fig. 6 Excitation function for ${ }^{89} \mathrm{Y}(\mathrm{p}, \mathrm{x})^{74}$ As.

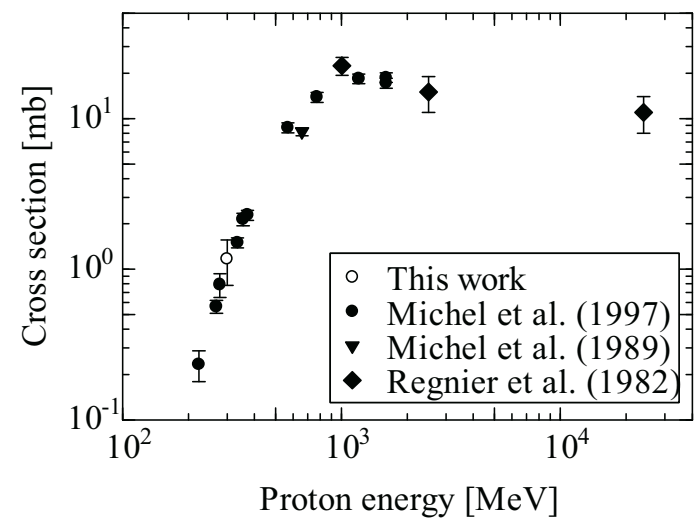

Fig. 7 Excitation function for ${ }^{89} \mathrm{Y}(\mathrm{p}, \mathrm{x})^{65} \mathrm{Zn}$. 
experimental value of ${ }^{89} \mathrm{Y}(\mathrm{n}, \mathrm{x})^{75} \mathrm{Br}$ reaction cross section is shown to be lower than the reference values in the proton cross sections.

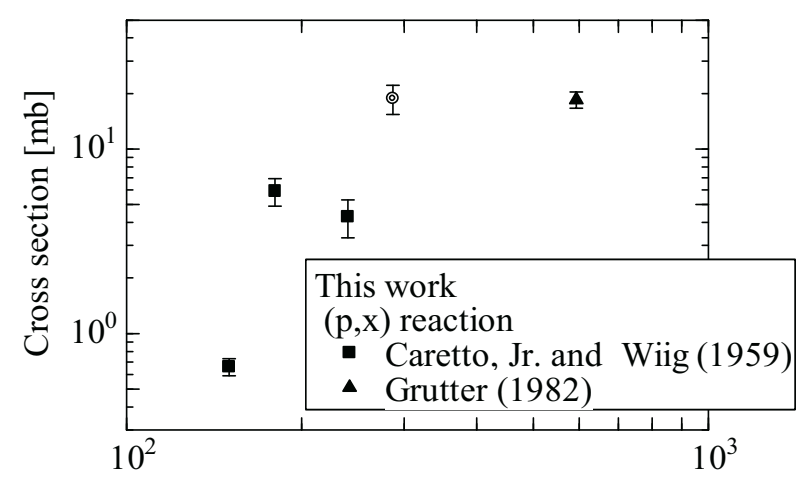

Neutron/Proton energy [MeV]

Fig. 8 Cross section obtained for ${ }^{89} \mathrm{Y}(\mathrm{n}, \mathrm{x}){ }^{77} \mathrm{Br}$ compared with cross sections for ${ }^{89} \mathrm{Y}(\mathrm{p}, \mathrm{x})^{77} \mathrm{Br}{ }^{11,12)}$.

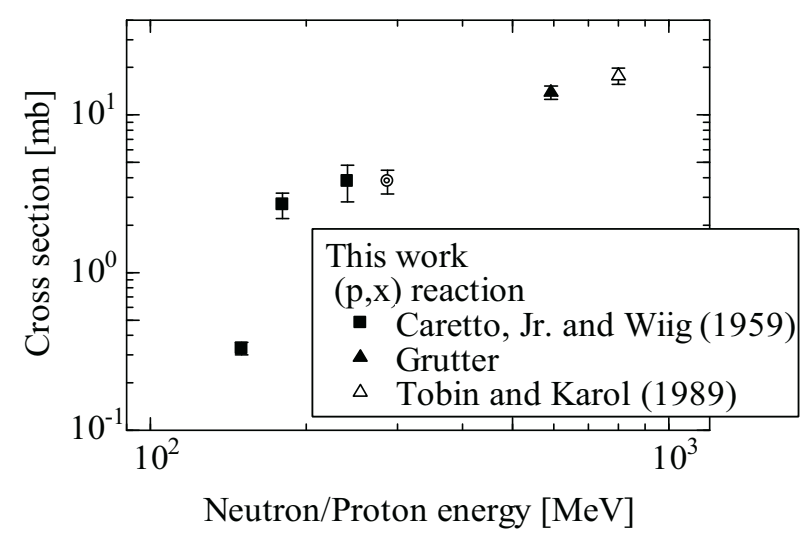

Fig. 9 Cross section obtained for ${ }^{89} \mathrm{Y}(\mathrm{n}, \mathrm{x})^{75} \mathrm{Br}$ compared with cross sections for ${ }^{89} \mathrm{Y}(\mathrm{p}, \mathrm{x})^{75} \mathrm{Br}{ }^{11-13)}$.

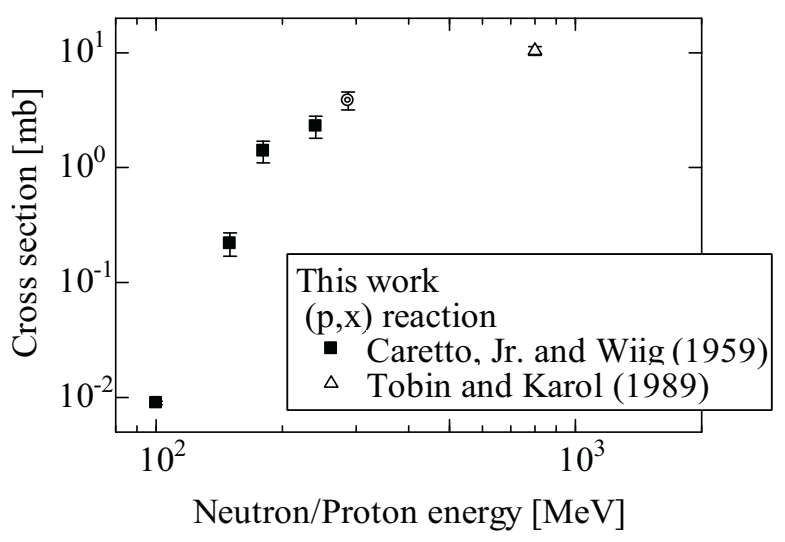

Fig. 10 Cross section obtained for ${ }^{89} Y(n, x){ }^{72} A$ s compared with cross sections for ${ }^{89} \mathrm{Y}(\mathrm{p}, \mathrm{x})^{72} \mathrm{As}{ }^{11,13)}$.

\section{Proton and neutron cross sections in Terbium}

The cross section data for ${ }^{159} \mathrm{~Tb}(\mathrm{p}, \mathrm{x}){ }^{149} \mathrm{Gd},{ }^{159} \mathrm{~Tb}(\mathrm{p}, \mathrm{x}){ }^{148} \mathrm{Eu}$,

${ }^{159} \mathrm{~Tb}(\mathrm{p}, \mathrm{x}){ }^{147} \mathrm{Eu}$ and ${ }^{159} \mathrm{~Tb}(\mathrm{p}, \mathrm{x}){ }^{145}$ Eu reactions were obtained.

The reference cross section data for those four proton-induced reactions have never been reported elsewhere.

Since the experimental proton cross sections in $\mathrm{Y}$ in this work agree well with the reference values, those in $\mathrm{Tb}$ are expected to be obtained successfully and shown in Fig. 11.

The cross section

data for

${ }^{159} \mathrm{~Tb}(\mathrm{n}, \mathrm{x}){ }^{149} \mathrm{Gd}$,

${ }^{159} \mathrm{~Tb}(\mathrm{n}, \mathrm{x}){ }^{148} \mathrm{Eu}$,

${ }^{159} \mathrm{~Tb}(\mathrm{n}, \mathrm{x}){ }^{147} \mathrm{Eu}$ and

${ }^{159} \mathrm{~Tb}(\mathrm{n}, \mathrm{x}){ }^{145} \mathrm{Eu}$,

where product

nuclides are same as

those in the above

four proton-induced

reactions, were

obtained and also

shown in Fig.11.

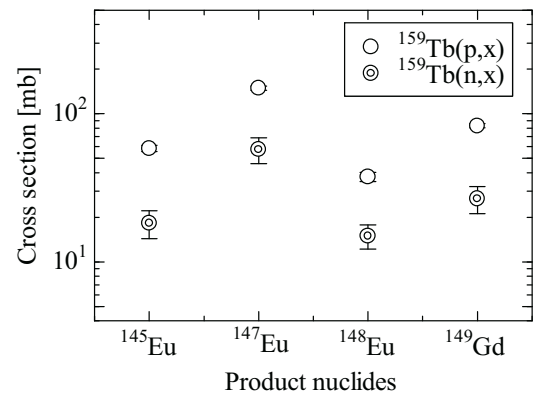

Fig. 11 Cross sections obtained for

${ }^{159} \mathrm{~Tb}(\mathrm{p}, \mathrm{x})$ and ${ }^{159} \mathrm{~Tb}(\mathrm{n}, \mathrm{x})$ reactions
Comparing the neutron-induced reaction cross sections with the proton ones in Fig. 11, it is shown that the neutron ones tend to be lower than the proton one. To evaluate those experimental neutron data in detail, further studies along this line, comparison of those data with values obtained from calculation codes, are in progress.

\section{Conclusion}

Reaction cross sections for $\mathrm{Y}$ and $\mathrm{Tb}$ induced by quasi-monoenergetic $287 \mathrm{MeV}$ neutron were measured. Proton-induced reaction cross sections for these elements at $300 \mathrm{MeV}$ were also measured.

The measured cross section data in the ${ }^{89} \mathrm{Y}(\mathrm{p}, \mathrm{x})$ reaction agree well with the reference values. Those in the ${ }^{89} \mathrm{Y}(\mathrm{n}, \mathrm{x}){ }^{77} \mathrm{Br}$ and ${ }^{89} \mathrm{Y}(\mathrm{n}, \mathrm{x}){ }^{72}$ As reaction approximately agree with the reference proton cross section data.

Those in the ${ }^{159} \mathrm{~Tb}(\mathrm{n}, \mathrm{x})$ reaction tend to be lower than those in the ${ }^{159} \mathrm{~Tb}(\mathrm{p}, \mathrm{x})$ reaction which are expected to be obtained successfully.

\section{Acknowledgment}

The authors express their gratitude to the accelerator staff of RCNP for their generous supports in this experiment (RCNP-E298). This work was supported by embryonic research project support in Kyoto University Global COE Program "International Center for integrated Research and Advanced Education in Materials Science" and National Science Foundation (EAR-0345817) for KN.

\section{References}

1) H. Yashima et al., J. Nucl. Sci. Technol. Supplement, 4, 70 (2004)

2) K. Nishiizumi et al., Goldschmidt Conf. Abst., Davos, Swizerland, Jun. 21-26, 2009, p.A945 (2009).

3) E. Kim et al., Nucl. Sci. Eng., 129, 209 (1998).

4) E. Kim et al., J. Nucl. Sci. Technol., 36[1], 29 (1999)

5) K. Ninomiya, et al., J. Nucl. Radiochem. Sci. Supplement, 9, 158 (2008).

6) J. M. Sisterson, et al., Nucl. Instrum. Meth. B, 240, 617 (2005)

7) H. Hirayama et al., SLAC-265, Stanford linear Accelerator 
Center, Stanford University (1985)

8) R. Michel et al., Nucl. Instrum. Meth. B, 240, 153 (1997).

9) S. Regnier et al., Phys. Rev. C, 26, 931 (1982).

10) R. Michel et al., J. Analyst (London) 114, 287 (1989).
11) A. A. Caretto, Jr. and E. O. Wiig, Phys. Rev. 115, 1238 (1959).

12) A. Grütter, J. Appl. Radiat. Isot. 33, 725 (1982).

13) M. J. Tobin and P. J. Karol, Phys. Rev. C, 39, 2330 (1989). 